\title{
Decreased Invasion of Urothelial Carcinoma of the Bladder by Inhibition of Matrix-Metalloproteinase 7
}

\author{
Christian Bolenz ${ }^{\mathrm{a}, 1, *}$, Daniel Knauf ${ }^{\mathrm{b}, 1}$, Axel John ${ }^{\mathrm{a}}$, Philipp Erben ${ }^{\mathrm{b}}$, Annette Steidler ${ }^{\mathrm{b}}$, \\ Stefan W. Schneider ${ }^{\mathrm{d}}$, Cagatay Günes ${ }^{\mathrm{a}}$ and Christian Gorzelanny ${ }^{\mathrm{c}, \mathrm{d}, *}$ \\ ${ }^{a}$ Department of Urology, University of Ulm, Ulm, Germany \\ ${ }^{\mathrm{b}}$ Department of Urology, Mannheim Medical Center, University of Heidelberg, Mannheim, Germany \\ ${ }^{\mathrm{c}}$ Department of Experimental Dermatology, Mannheim Medical Center, University of Heidelberg, \\ Mannheim, Germany \\ ${ }^{\mathrm{d}}$ Department of Dermatology and Venerology, University Hospital Hamburg-Eppendorf, Hamburg, Germany
}

\begin{abstract}
.
Objectives: To measure and to modulate the invasive potential of urothelial carcinoma of the bladder (UCB) cells in a standardized preclinical setting using broad-spectrum matrix-metalloproteinase (MMPs) inhibitors and specific targeting of MMP7.

Materials and Methods: MMP expression levels in UCB cells were determined by quantitative real-time PCR (qRT-PCR) and gel zymographies of cell supernatants (MMP9, MMP2 and MMP1) and cell lysates (MMP7). The invasiveness of human UCB cells (HT1197 and T24/83) and human benign urothelial cells (UROtsa) was modulated by a broad-spectrum MMP inhibitor (4-Aminobenzoyl-Gly-Pro-D-Leu-D-Ala hydroxamic acid; AHA) and by MMP7 specific siRNAs. MMP7 knockdown efficiency was assessed by qRT-PCR and western blot. Invasive potential of UCB cells was measured by a standardized trans-epithelial electrical resistance (TEER) assay.

Results: Different MMP secretion profiles were measured in UCB cells. The active form of MMP7 was exclusively detected in HT1197 cells. Characteristic TEER breakdown patterns were observed in UCB cells when compared to benign cells. Invasive potentials were significantly higher in HT1197 cells than in T24/83 and in UROtsa cells [14.8 \pm 5.75 vs. $1.5 \pm 0.56$ and $1.2 \pm 0.15$, respectively; $p<0.01]$. AHA treatment reduced the invasive potential of HT1197 cells. Also the specific downregulation of MMP7 by siRNA lowered the HT1197 cell invasiveness [20 \pm 1.0 vs. $16 \pm 2.8 ; p<0.05]$. Neither AHA nor MMP-7 siRNA transfection altered the invasive potential of T24/83 cells.

Conclusions: Invasion of UCB is partially dependent on MMPs. Specific targeting of MMP7 by siRNA reduces the invasive potential in a subgroup of UCB cells. Therefore, MMP7 represents a potential therapeutic target which warrants further investigation.
\end{abstract}

Keywords: Urologic neoplasms, urothelial carcinoma, bladder cancer, metastasis, invasion, matrix-metalloproteinases

\footnotetext{
${ }^{1}$ These authors contributed equally to this work.

*Correspondence to: Christian Gorzelanny, Department of Urology, University of Ulm, Ulm, Germany. E-mail: christian. gorzelanny@medma.uni-heidelberg.de and Christian Bolenz. E-mail: christian.bolenz@uniklinik-ulm.de.
}

\section{INTRODUCTION}

The incidence of urothelial carcinoma of the urinary bladder is steadily increasing, with an estimated 79,030 new cases and 16,870 deaths in the United 
States in 2017 [1]. The leading cause of cancerrelated mortality is the metastatic dissemination of the disease [2]. Therapeutic options for metastatic UCB are limited. Standard systemic chemotherapy provides only a small improvement in overall survival, indicating a clear need of new therapeutic approaches [3].

Several histopathological parameters have been established to improve prediction of the individual cancer biology $[4,5]$. However, the early functional processes during metastasis formation are complex, involving a plethora of acting molecules and cell types. The modulation of the extracellular matrix (ECM) is a crucial event in the highly regulated multi-step process of metastatic spread, including the action of MMPs [6-9]. The MMP family consists of more than 20 different proteases which contribute to physiological processes such as wound healing. However, they are also involved in pathologic conditions such as the formation of metastasis [8]. In UCB, MMP2, MMP7 and MMP9 are considered to be amongst the most relevant MMPs defining the potency of the tumor cell to spread [10-12].

MMP7 is the smallest member of the MMP family and lacks a typical hemopexin domain which is otherwise known to confer substrate specificity. The resulting broad enzymatic activity against different major components of the ECM and the basal membrane (Fibronectin, laminin, type IV collagen, proteoglycans, VE-cadherin) suggests a prominent role in early cancer invasion and metastasis formation in UCB [10]. Furthermore, MMP7 may cleave and thereby activate MMP2 and MMP9 zymogens as well as the precursor proteins of tumor necrosis factors [13]. Multiple sources are known to contribute to elevated MMP levels in tumor tissue, e.g. tumor associated fibroblasts for MMP2 and inflammatory cells such as neutrophils and macrophages for MMP9 [9, 14]. Conversely, expression analysis confirmed tumor cells as the principle origin of MMP7 [15]. Clinical data seem to support a pathophysiological role of MMP7 in UCB. Elevated serum, urine and tissue MMP7 levels were detected in patients with lymph node positive bladder cancer. Moreover, high MMP7 serum concentrations proved to be an independent and unfavorable predictor for diseasespecific survival $[16,17]$. Svatek et al. validated the negative prognostic role of MMP7 in an independent cohort of bladder cancer patients while MMP1, MMP2, MMP3, MMP8 and MMP9 levels showed no correlation [18].
We aimed to measure the specific effects of MMP inhibition, focusing on the functional role of MMP7 during the initial phase of the metastatic cascade. For this purpose, we used a previously established electrophysiological preclinical assay which allows standardized assessments of the invasive potential of UCB cells [19]. This assay measures the transepithelial electrical resistance (TEER) of an epithelial monolayer formed by the high-resistance MadinDarby canine kidney (MDCK)-C7 cell line [20]. The TEER assay has been widely used to measure the invasive potential of cancer cells and inflammatory fibroblasts [19, 21-23]. In contrast to filter-based transmigration assays (e.g. Boyden chamber), the TEER assay is already sensitive to secreted proteases, mimicking the early cross-talk between invading cells and the surrounding tissue [24].

\section{MATERIAL AND METHODS}

\section{Cell lines}

The human UCB cell lines HT1197 and T24/83 were used. Both cell lines were obtained from the European Collection of Authenticated Cell Cultures (ECACC). The benign simian virus 40 (SV40) large $\mathrm{T}$ antigen immortalized UROtsa cell line served as a control. Cells were cultured in $75 \mathrm{~cm}^{2}$ flasks in cell culture medium, containing minimal essential medium for HT1197 and McCoy medium for T24/83, supplemented with $10 \%$ fetal bovine serum and $2 \mathrm{mM}$ glutamine. The incubation was performed at $37^{\circ} \mathrm{C}$ in humid atmosphere of $5 \% \mathrm{CO}_{2}$. Twice a week the media were changed with sub-cultivation at 70 to $80 \%$ of confluency.

\section{Invasion assay}

The invasive potential of UCB cells was measured with a previously described electrophysiological assay [19, 21, 22]. A schematic drawing of the technical setup is illustrated in Fig. 1A. The assays based on the co-cultivation of carcinoma cells with high resistance MDCK-C7 cells which form an electrically tight epithelial monolayer. MDCK-C7 cells were cultivated in MEM medium (PAA, Pasching, Austria) supplemented with $10 \%$ FCS, $1 \%$ L-Glutamine and $1 \%$ antibiotics and maintained at $37^{\circ} \mathrm{C}$ in a humidified $5 \% \mathrm{CO}_{2}$ atmosphere. Cells were grown to confluence on the inverse side of a filter cup insert (growth area, $4.2 \mathrm{~cm}^{2}$; pore diameter: $0.4 \mu \mathrm{m}$; thickness, $20 \mu \mathrm{m}$; BD, USA). To maintain the cells, medium 

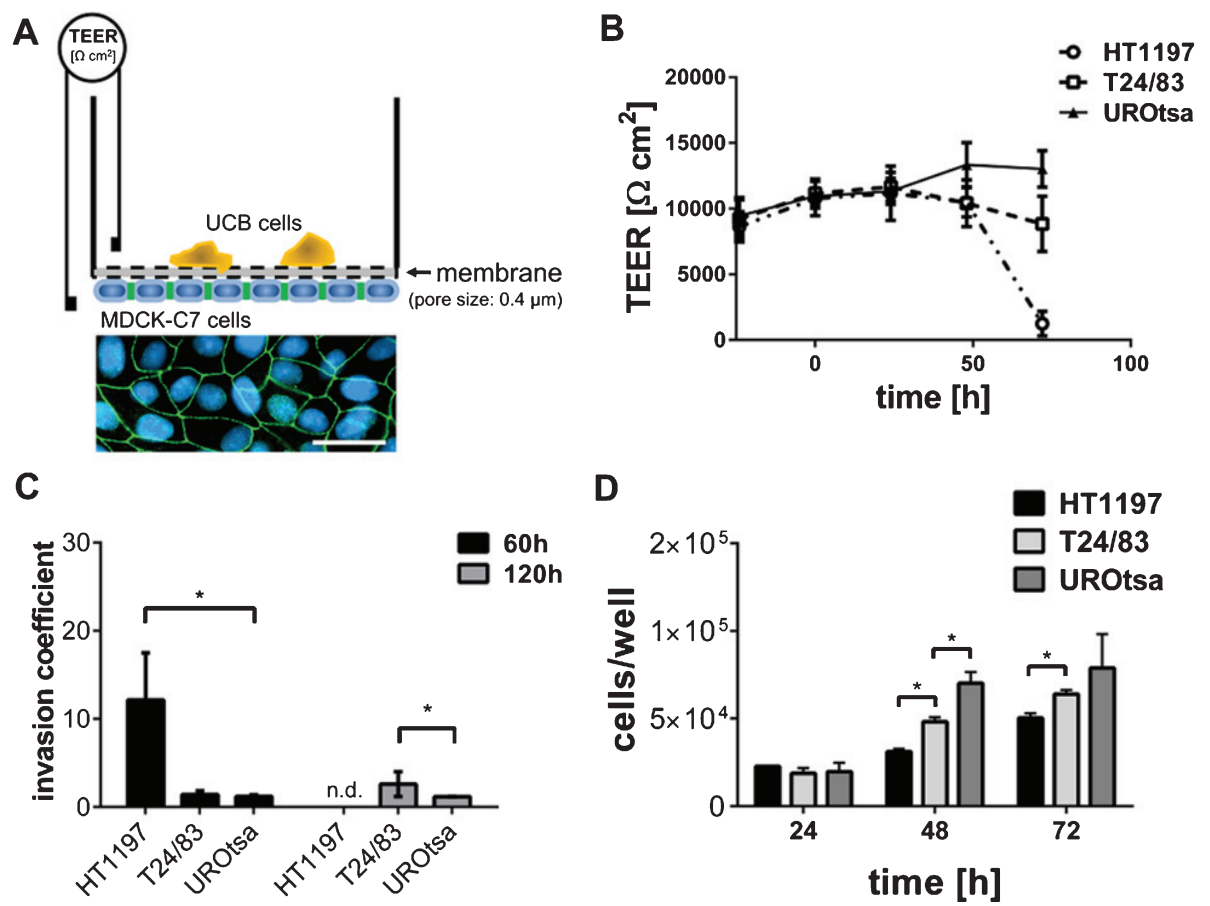

Fig. 1. Invasive properties of UCB cells. (A) The TEER assay depends on a high electrically resistant MDCK-C7 cell layer, seeded upside down into a filter cup insert. UCB cells were cultivated in the upper compartment of the filter cup. Therefore, MDCK-C7 cells were physically separated from the UCB cells limiting the communication of both cell types to released molecules. Immunofluorescence staining of MDCK-C7 cells documents the formation of tight junctions. Tight junctions were detected by zonula occludens 1 specific antibodies (green). Cell nuclei were stained in blue using 4',6-Diamidin-2-phenylindol. Scale corresponds to $50 \mu \mathrm{m}$. (B) The dynamic development of the trans-epithelial electrical resistance (TEER) as a function of time. The invasive potential of malignant HT1197 and T24/83 cells was compared to that of the benignant urothelial cell line UROtsa. TEER was followed for three days after challenging the MDCK-C7 epithelial layer $(t=0 \mathrm{~h})$. (C) Invasion coefficients were calculated with equation 1 and invasive properties $60 \mathrm{~h}$ and $120 \mathrm{~h}$ after carcinoma cells addition were compared. HT1197 caused the strongest TEER breakdown. (D) Proliferation rate of the UCB cells was of a comparable magnitude whereas HT1197 showed the lowest cell growth and UROtsa cells had the highest cell increment. n.d.: not detectable, ${ }^{*} P<0.05 t$-test.

was changed every $24 \mathrm{~h}$. Co-cultivation with malignant or benignant cells (concentration $10^{6}$ cells) was started $72 \mathrm{~h}$ after seeding the MDCK-C7 cells. TEER was measured with $\mathrm{Ag} / \mathrm{AgCl}$ chopstick electrodes connected to an ohmmeter (EVOM, World Precision Instruments, USA). Obtained data were normalized and the invasive potential was calculated using equation 1.

$$
\text { invasive potential }=\frac{\text { TEER }_{0}}{\text { TEER }_{\mathrm{t}}}
$$

TEER $_{0}$ corresponds to the TEER value prior to the addition of UCB cells to the MDCK-C7 cell layer. TEER $_{t}$ corresponds to the TEER values obtained at indicated points in time $(60 \mathrm{~h}, 120 \mathrm{~h})$.

\section{Proliferation assay}

Proliferation was measured in 96-well plates using the WST-1 assay (Sigma-Aldrich, USA). The assay was performed according to the manufactures' protocol.

\section{Gel zymography}

Gel zymography was used to measure the activity of MMPs semi-quantitatively in the supernatants or cell lysates of UCB cells. Supernatants and cells were harvested after $48 \mathrm{~h}$ of cultivation in medium without serum. Gelatine zymographies were used to detect MMP2, MMP9 and MMP1 whereas casein was used as substrate for MMP7. Zymographies were performed as previously described $[25,26]$.

\section{MMP Inhibition}

To investigate the effect of unspecific MMP modulation, we added the broad-spectrum inhibitor 4-Aminobenzoyl-Gly-Pro-D-Leu-D-Ala hydroxamic acid (AHA; Sigma-Aldrich, USA) at a concentration of $0.5 \mu \mathrm{g} / \mathrm{ml}$. Due to the specific design and structure of AHA it is able to complex with the MMP 
active site zinc ion and thereby inhibits a multitude of collagenases and gelatinases [27, 28].

\section{siRNA Transfection}

The siRNA transfection followed manufacturers' instructions using Lipofectamine ${ }^{\circledR} 2000$ as a transfection reagent. Optimal amounts of the different components were determined previously. Prior to the invasion experiments we compared the knockdown efficiency of two distinct siRNAs using qRT-PCR. For quantitative analysis of MMP7 gene silencing, HT1197 cells were transfected with two different siRNAs (Hs_MMP7_5 (MMP7_5), Hs_MMP7_6 (MMP7_6), Qiagen, Netherlands). The siRNAs had the following sequences: MMP7 5:5'-ACC CAT TTG ATG GGC CAG GAA-3‘; MMP7_6:5‘-TGC AGT GAT GTA TCC AAC CTA-3‘. The Silencer ${ }^{\circledR}$ Select Negative Control No. 1 siRNA (siCo, life technologies, USA) served as a control. To attenuate the invasive potential, UCB cells were transfected 5 hours prior to seeding in the invasion assay using $50 \mathrm{pmol}$ of siRNA. Coefficients were normalized to UCB cells transfected with siCo.

\section{Quantitative real time PCR ( $q R T-P C R)$}

UCB cell RNA was extracted using RNeasy Mini Kit (Qiagen, Netherlands) and followed the manufacturers' instructions. For cDNA synthesis, random hexamers were used. MMP7 mRNA gene expression levels were determined by qRT-PCR using AmpliTaq ${ }^{\circledR}$ Fast DNA-Polymerase (life technologies, USA) and StepOnePlus ${ }^{\circledR}$ Real-Time PCR System (life technologies, USA). The mRNA gene expression levels of $B$-glucuronidase (GUS) served as the endogenous control [29]. For quantitative analysis we referred to the comparative $\mathrm{C}_{\mathrm{T}}$ method [30].

\section{Western blot}

Cultured UCB cells were pelleted and lysed with lysis buffer (50 mM Tris/HCl, $\mathrm{pH} 7.4 ; 150 \mathrm{mM} \mathrm{NaCl}$; $1 \mathrm{mM}$ EDTA; $1 \mathrm{mM}$ EGTA; $10 \%$ glycerol and 1\% Triton-X 100). Protein concentration was quantified using the Bradford assay. Equal amounts of protein samples $(50 \mu \mathrm{g} / \mathrm{lane})$ were separated by sodium dodecyl sulfate-polyacrylamide gel electrophoresis (SDS-PAGE) and immunoblotting was performed as previously described [21]. MMP7 was detected with a monoclonal mouse $\operatorname{IgG}_{2 B}$ antibody ( $R \& D$ systems, USA). As control, $\beta$-actin was detected with a monoclonal $\operatorname{IgG}_{1}$ antibody (Sigma-Aldrich, USA).

\section{Statistical analysis}

Values are presented as mean \pm standard deviation (SD). At least three independent measures were performed in each setting. Statistical analysis was performed with GraphPad Prism 6 software. We applied the unpaired Student's $T$-test and the non-parametric Mann-Whitney $\mathrm{U}$ test to evaluate statistical significance. $P$-values below 0.05 were considered as significant.

\section{RESULTS}

The experimental setup of the TEER assay is shown in Fig. 1A. MDCK-C7 cells are known to form tight cell junctions as indicated by TEER values above $10,000 \mathrm{ohm} * \mathrm{~cm}^{2}$ [31]. Breakdown patterns of the TEER assay were strongly time-dependent, requiring a co-culture of MDCK-C7 and UCB cells of several hours to days to induce a total TEER breakdown (Fig. 1B).

Benign UROtsa cells did not exhibit any invasive potential when compared to malignant T24/83 or HT1197 cells (Fig. 1B). The corresponding invasion coefficients were calculated using equation 1 . HT1197 cells showed the highest invasive potential with an invasion coefficient of $14.8 \pm 5.75$ after $60 \mathrm{~h}$ of co-culturing. The initial moderate difference between T24/83 and UROtsa cells $(1.5 \pm 0.56$ vs. $1.2 \pm 0.15$ ) became significantly different after $120 \mathrm{~h}$ $(2.8 \pm 1.62$ vs. $1.3 \pm 0.09 ; p<0.01$; Fig. 1C). To exclude that the HT1197 cell-induced TEER breakdown was related to a higher proliferation rate and therefore to an elevated nutrient consumption we performed a WST-1 assay. Figure 1D shows that the cell growth of HT1197 cells was lowest, suggesting that the high invasive potential is not because of an excessive cell proliferation.

Based on previous studies indicating that MMPs trigger the invasion of tumor cells, we quantified the expression of several MMPs by qRT-PCR. Figure 2A shows that the benign UROtsa cell line expresses high levels of MMP1 and MMP2 and relatively low levels of tissue inhibitors of MMP (TIMP) 1 and 2. The malignant UCB cells expressed only low levels of almost all MMPs, whereas TIMP1 and TIMP2 were secreted in high amounts. 


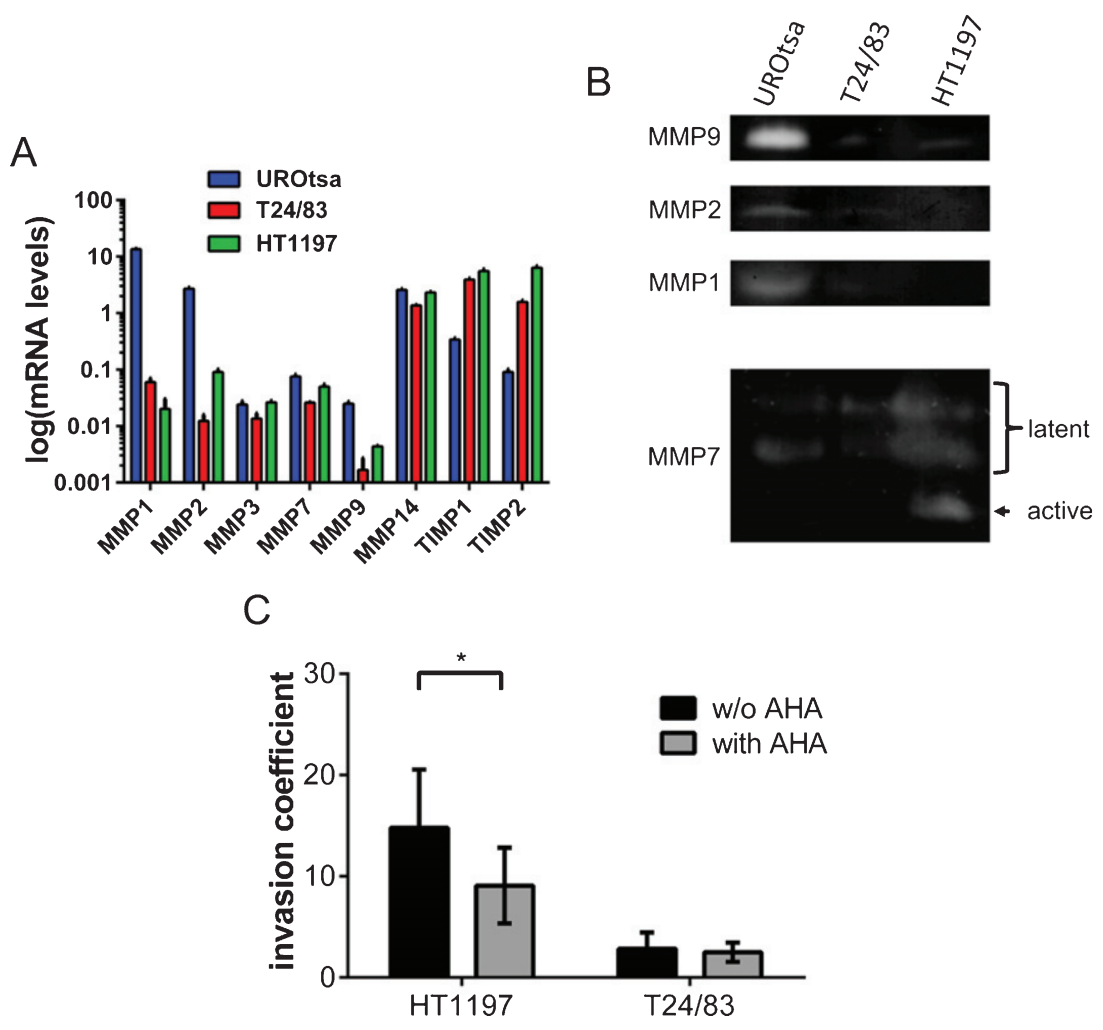

Fig. 2. Profiling of MMP expression and the impact of MMPs on the invasive potential of bladder cancer cells. (A) Gene expression of various MMPs was compared by qRT-PCR. UROtsa cells were characterized by a high expression of MMP1 and MMP2. HT1197 and T24/83 showed relatively high levels of TIMP1 and TIMP2 expression. (B) Gel zymographies were used to measure the activity of MMPs in supernatants (MMP9, MMP2, MMP1) and cell lysates (MMP7) of UCB cells. Supernatants of UROtsa cells contain highest levels of MMP9, MMP2 and MMP1. However, malignant cell lines secreted only minor amounts of the corresponding MMPs. Latent forms of MMP7 were detected in all cell lysates, whereas the active form of MMP7 was only found in HT1197 cells. (C) The broad spectrum MMP inhibitor AHA attenuates significantly the invasive potential of HT1197 but not of T24/83 cells $60 \mathrm{~h}$ after seeding of the UCB cells. ${ }^{*} P<0.05 t$-test.

To substantiate the transcriptional analysis, we have performed gel zymographies of cell supernatants (MMP9, MMP2 and MMP1) and cell lysates (MMP7) using gelatin or casein as substrates, respectively (Fig. 2B). In agreement with the qRT-PCR data, we found that UROtsa cell released high amounts of MMP9, MMP2 and MMP1. The levels of these MMPs were close to the detection limit in T24/83 and HT1 197 cells. In contrast, MMP7 was found in all tested cell lysates. However, the active form of MMP7 was only present in lysates of HT1197 cells (Fig. 2B).

To further characterize the impact of MMPs on the invasive potential of the malignant UCB cells, we analyzed the influence of the broad spectrum MMP inhibitor AHA within our invasion assay (Fig. 2C). The addition of AHA $(0.5 \mu \mathrm{g} / \mathrm{ml})$ significantly reduced the invasive potential of HT1197 cells [invasive coefficient $14.8 \pm 5.75$ vs. $9.4 \pm 4.26 ; p<0.05$ ] In contrast, AHA had no impact on the behavior of T24/83 cells.
The active form of MMP7 was exclusively detected in HT1197 cell but not in UROtsa or T24/83 cells. The impact of MMP7 was further investigated using MMP7-specific siRNAs. Prior to the invasion experiments, we compared the two distinct MMP7 siRNAs, MMP7_5 and MMP7_6. Knockdown efficiencies were measured by western blot and by qRT-PCR (Fig. 3). Both siRNAs silenced the expression of MMP7 in HT1196 cells when compared with scrambled control siRNA (siCO). The strongest knockdown effect [91 $\pm 9.5 \% ; p<0.01]$ was observed $21 \mathrm{~h}$ after cell transfection using the MMP7_6 siRNA [vs. 66 $\pm 10.1 \%$ with MMP7_5 siRNA; $p>0.05$ ] (Fig. 3A). A comparable knockdown efficiency of MMP7 was detected by western blot analysis (Fig. 3B). Therefore, subsequent invasion assays were performed with the MMP7_6 siRNA.

MMP7 silencing in HT1197 cells reduced their invasiveness significantly [invasion coefficient 
A

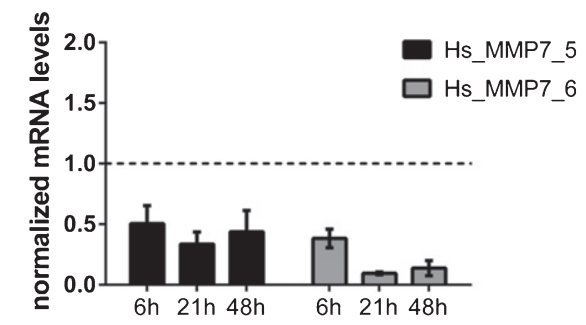

B

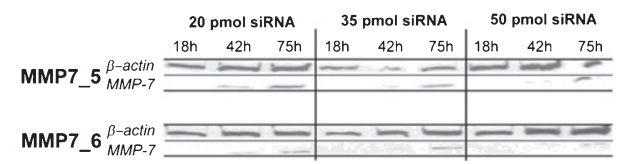

Fig. 3. (A) MMP7 gene silencing using small interfering RNAs (siRNAs) in HT1197 cells. Knockdown efficiencies of two distinct siRNAs (MMP7_5, MMP7_6) were determined at indicated post-transfection time points using qRT-PCR. The knockdown efficiency was normalized to cells transfected with scrambled siRNA $(\mathrm{siCo}=1$, dashed line). (B) Western blot analysis of cells treated with different amounts of siRNAs $(20,35,50$ pmol) were performed $18 \mathrm{~h}, 42 \mathrm{~h}$ and $75 \mathrm{~h}$ post-transfection.

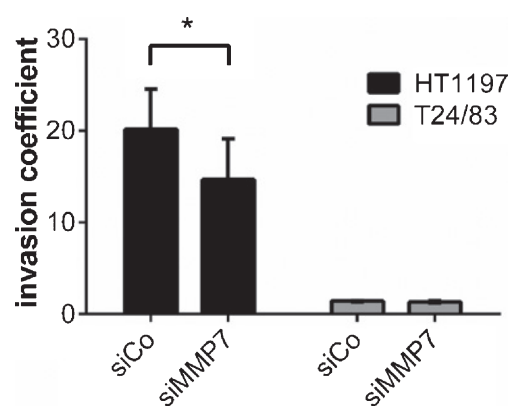

Fig. 4. Impact of MMP7 knockdown on UCB cell invasiveness $60 \mathrm{~h}$ after seeding the carcinoma cells. Silencing of MMP7 attenuated the invasive potential HT1197. Invasiveness of T24/83 cells was not affected. ${ }^{*} P<0.05 t$-test.

$20 \pm 1$ vs. $16 \pm 2.8 ; p<0.05]$. In contrast, knockdown of MMP7 in T24/83 cells failed to decrease their invasive potential (Fig. 4).

\section{DISCUSSION}

The formation of metastasis is the leading cause of cancer-related mortality and its prevention remains a major therapeutic challenge. Only surrogate markers of micrometastatic disease such as lymphovascular invasion have been described and current therapies have limited efficacy in metastatic stages of UCB [3,
5]. Factors involved in the metastatic cascade need to be identified and their functional role characterized in order to identify potential therapeutic targets, preferably in the early process of cell dissemination. We used an experimental setting of TEER measurements, preventing direct physical contact between UCB cells and the barrier-forming epithelial cell layer. Therefore, only secreted factors such as MMPs contribute to the measured invasive potential of the UCB cells. Indeed, our previous studies on other tumor entities demonstrated that different proteases and MMPs are responsible for the breakdown of barriers and consequently of the TEER [31, 32]. There is growing evidence that the enzyme group of MMPs may be critically involved in the invasive process and metastatic cascade of UCB, particularly MMP2, MMP7 and MMP9 [10]. MMP7 is of high interest because its expression correlates significantly with the development of metastasis and other oncological end points $[10,16,33]$. The underlying molecular mechanisms are unknown and we can only speculate about the possible molecular action of MMP7 within our assays. MMP7 is able to interact with cell surface-associated glycosaminoglycans and it remains associated with the plasma membrane after secretion [34]. After its activation, MMP7 is then able to release cell surface bound proteins such as tumor necrosis factor $\alpha$ [35]. Previously, we could prove that melanoma-derived heparanase boosts cancer cell invasion through the release of vascular endothelial growth factor A from glycosaminoglycans suggesting a comparable molecular mechanism [21].

Several clinical trials assessed the potential therapeutic effect of MMP inhibition in different tumor entities [11, 36, 37]. However, severe side effects and a lack of clinical benefit were observed after the application of broad spectrum MMP-inhibitors preventing their wide-spread application in oncology [37]. An unspecific targeting by these inhibitors and miscellaneous physiological substrates for MMPs may explain clinical failure $[11,12]$. In line with that, we have recently reported that UROtsa cells but not HT1197 cells release a high amount of MMP2 and MMP9, indicating that the invasiveness of HT1197 cells is not directly linked to the secretion of these MMPs [19]. In the present study, we have again confirmed this discrepancy between MMP2 and MMP9 expression and cell invasion.

However, we were able to demonstrate that an undirected modulation of MMPs with the broadspectrum inhibitor AHA resulted in a significant 
reduction of the invasive potential of HT1197 cells. Because the invasive capacity of T24/83 cells is comparatively low, it is likely that the potential effect of AHA is beneath the detection limit of our TEER assay.

To further elucidate which of MMP contributes to the invasiveness of HT1197 cells, we have followed the hypothesis of Szarvas and co-workers who argued that MMP7 is a major driver of UCB cell dissemination in vivo [16-18, 33]. Indeed, we could prove by gel zymography that only HT1197 cells produce an active MMP7 but not UROtsa and T24/83 cells, supporting the previous hypothesis. To better consolidate the role of MMP7, we applied specific siRNAs to induce a transient silencing of the MMP7 expression in HT1197 and T24/83 cells.

In line with the findings of Szarvas et al., we observed a significant reduction of the invasiveness of HT1197 cells after MMP7 knockdown [17]. As expected from the experiments with AHA, the MMP7 siRNA had no effect on the T24/83 cells.

Tumor cell invasion is a complex and highly regulated process mediated not only by the invading cells but also by neighboring cells from the tumor microenvironment [38]. Besides tumor-derived MMPs, a relevant amount of proteases with stromal origin may contribute to the invasive phenotype of UCB cells [39]. UCB invasion is complex and depends on various key player molecules of which MMP7 represents only one aspect. We are aware that our study is inherently limited by its in vitro design, limiting the transfer of our results to a complex in vivo situation. Despite this limitation we noted a high variability of the invasive potential among the tested cell lines, corroborating the general idea of a patient-oriented therapy considering the individual tumor biology. Our results support the hypothesis that at least a subgroup of UCB patients might be treated by specific MMP7 targeting, thereby reducing the risk of invasive cancer growth and the formation of metastasis. Taking the existing in vivo data into account innovative trial design employing specific MMP7 inhibition or improved drug delivery systems would be needed to validate the potential clinical significance of MMP7 targeting. Although the cell lines used in the present study cannot reflect the entire tumor biology of UCB in vivo, the presented data provide basic mechanistic insights into the complex regulation of proteases and MMPs in bladder cancer. Further studies, including experimental UCB mouse models that are currently established in our laboratory, will further substantiate the biological impact of different invasion mechanisms.

\section{CONCLUSIONS}

Downregulation of MMP7 by siRNA may reduce the invasive potential of UCB, thus interrupting the metastatic cascade in an early stage of cancer cell dissemination. At least in a subgroup of UCB, specific MMP7 targeting may represent a promising therapeutic option and warrants further investigation.

\section{ACKNOWLEDGMENTS}

We thank Natalia Halter and Ewa Wladykowski for excellent technical support. This work was supported by the Deutsche Forschungsgemeinschaft within the SFB/Transregio 23 (project A9 to SWS) and the RTG2099.

\section{REFERENCES}

[1] Siegel RL, Miller KD, Jemal A. Cancer statistics, 2016. CA: A Cancer Journal for Clinicians 2016;66(1):7-30.

[2] Kaufman DS, Shipley WU, Feldman AS. Bladder cancer. Lancet 2009;374(9685):239-49.

[3] von der Maase H, Sengelov L, Roberts JT, Ricci S, Dogliotti L, Oliver T, Moore MJ, Zimmermann A, Arning M. Longterm survival results of a randomized trial comparing gemcitabine plus cisplatin, with methotrexate, vinblastine, doxorubicin, plus cisplatin in patients with bladder cancer. Journal of Clinical Oncology: Official Journal of the American Society of Clinical Oncology 2005;23(21):4602-8.

[4] Shariat SF, Karakiewicz PI, Palapattu GS, Lotan Y, Rogers CG, Amiel GE, Vazina A, Gupta A, Bastian PJ, Sagalowsky AI, Schoenberg MP, Lerner SP. Outcomes of radical cystectomy for transitional cell carcinoma of the bladder: A contemporary series from the Bladder Cancer Research Consortium. J Urol 2006;176(6 Pt 1):2414-22; discussion 22.

[5] Bolenz C, Herrmann E, Bastian PJ, Michel MS, Wulfing C, Tiemann A, Buchner A, Stief CG, Fritsche HM, Burger M, Wieland WF, Hofner T, Haferkamp A, Hohenfellner M, Muller SC, Strobel P, Trojan L. Lymphovascular invasion is an independent predictor of oncological outcomes in patients with lymph node-negative urothelial bladder cancer treated by radical cystectomy: A multicentre validation trial. BJU International 2010;106(4):493-9.

[6] Fidler IJ. The pathogenesis of cancer metastasis: The 'seed and soil' hypothesis revisited. Nature Reviews Cancer 2003;3(6):453-8.

[7] van Zijl F, Krupitza G, Mikulits W. Initial steps of metastasis: Cell invasion and endothelial transmigration. Mutation Research 2011;728(1-2):23-34. 
[8] Egeblad M, Werb Z. New functions for the matrix metalloproteinases in cancer progression. Nature Reviews Cancer 2002;2(3):161-74.

[9] Kessenbrock K, Plaks V, Werb Z. Matrix metalloproteinases: Regulators of the tumor microenvironment. Cell 2010;141(1):52-67.

[10] Szarvas T, vom Dorp F, Ergun S, Rubben H. Matrix metalloproteinases and their clinical relevance in urinary bladder cancer. Nature Reviews Urology 2011;8(5):241-54.

[11] Coussens LM, Fingleton B, Matrisian LM. Matrix metalloproteinase inhibitors and cancer: Trials and tribulations. Science 2002;295(5564):2387-92.

[12] Overall CM, Kleifeld O. Tumour microenvironment opinion: Validating matrix metalloproteinases as drug targets and anti-targets for cancer therapy. Nature Reviews Cancer 2006;6(3):227-39.

[13] Yokoyama Y, Grunebach F, Schmidt SM, Heine A, Hantschel M, Stevanovic S, Rammensee HG, Brossart P. Matrilysin (MMP-7) is a novel broadly expressed tumor antigen recognized by antigen-specific $\mathrm{T}$ cells. Clinical Cancer Research: An Official Journal of the American Association for Cancer Research 2008;14(17):5503-11.

[14] Wallard MJ, Pennington CJ, Veerakumarasivam A, Burtt G, Mills IG, Warren A, Leung HY, Murphy G, Edwards DR, Neal DE, Kelly JD. Comprehensive profiling and localisation of the matrix metalloproteinases in urothelial carcinoma. British Journal of Cancer 2006;94(4): 569-77.

[15] Ii M, Yamamoto H, Adachi Y, Maruyama Y, Shinomura Y. Role of matrix metalloproteinase-7 (matrilysin) in human cancer invasion, apoptosis, growth, and angiogenesis. Experimental Biology and Medicine 2006;231(1):20-7.

[16] Szarvas T, Singer BB, Becker M, Vom Dorp F, Jager T, Szendroi A, Riesz P, Romics I, Rubben H, Ergun S. Urinary matrix metalloproteinase-7 level is associated with the presence of metastasis in bladder cancer. BJU International 2011;107(7):1069-73.

[17] Szarvas T, Becker M, vom Dorp F, Gethmann C, Totsch M, Bankfalvi A, Schmid KW, Romics I, Rubben H, Ergun $\mathrm{S}$. Matrix metalloproteinase-7 as a marker of metastasis and predictor of poor survival in bladder cancer. Cancer Science 2010;101(5):1300-8.

[18] Svatek RS, Shah JB, Xing J, Chang D, Lin J, McConkey DJ, Wu X, Dinney CP. A multiplexed, particle-based flow cytometric assay identified plasma matrix metalloproteinase-7 to be associated with cancer-related death among patients with bladder cancer. Cancer 2010;116(19):4513-9.

[19] Bolenz C, Gorzelanny C, Knauf D, Keil T, Steidler A, Halter N, Martini T, Schneider SW. Assessing the invasive potential of bladder cancer: Development and validation of a new preclinical assay. J Urol 2013;189(5):1939-44.

[20] Wünsch S, Gekle M, Kersting U, Schuricht B, Oberleithner H. Phenotypically and karyotypically distinct Madin-Darby canine kidney cell clones respond differently to alkaline stress. Journal of Cellular Physiology 1995;164(1): 164-71.

[21] Yang Y, Gorzelanny C, Bauer AT, Halter N, Komljenovic D, Bauerle T, Borsig L, Roblek M, Schneider SW. Nuclear heparanase-1 activity suppresses melanoma progression via its DNA-binding affinity. Oncogene 2015;34(47):5832-42.

[22] Zak J, Schneider SW, Eue I, Ludwig T, Oberleithner H. High-resistance MDCK-C7 monolayers used for measuring invasive potency of tumour cells. Pflugers Archiv: European Journal of Physiology 2000;440(1):179-83.
[23] Wunrau C, Schnaeker EM, Freyth K, Pundt N, Wendholt D, Neugebauer K, Hansen U, Pap T, Dankbar B. Establishment of a matrix-associated transepithelial resistance invasion assay to precisely measure the invasive potential of synovial fibroblasts. Arthritis Rheum 2009;60(9): 2606-11.

[24] Schnaeker EM, Ossig R, Ludwig T, Dreier R, Oberleithner H, Wilhelmi M, Schneider SW. Microtubule-dependent matrix metalloproteinase-2/matrix metalloproteinase-9 exocytosis: Prerequisite in human melanoma cell invasion. Cancer Res 2004;64(24):8924-31.

[25] Gorzelanny C, Poppelmann B, Strozyk E, Moerschbacher BM, Schneider SW. Specific interaction between chitosan and matrix metalloprotease 2 decreases the invasive activity of human melanoma cells. Biomacromolecules 2007;8(10):3035-40.

[26] Troeberg L, Nagase H. Zymography of Metalloproteinases. Current Protocols in Protein Science: John Wiley \& Sons, Inc.; 2001.

[27] Odake S, Okayama T, Obata M, Morikawa T, Hattori $\mathrm{S}$, Hori H, Nagai Y. Vertebrate collagenase inhibitor. II. Tetrapeptidyl hydroxamic acids. Chemical \& Pharmaceutical Bulletin 1991;39(6):1489-94.

[28] Bauer AT, Burgers HF, Rabie T, Marti HH. Matrix metalloproteinase-9 mediates hypoxia-induced vascular leakage in the brain via tight junction rearrangement. Journal of Cerebral Blood Flow and Metabolism: Official Journal of the International Society of Cerebral Blood Flow and Metabolism 2010;30(4):837-48.

[29] Beillard E, Pallisgaard N, van der Velden VH, Bi W, Dee R, van der Schoot E, Delabesse E, Macintyre E, Gottardi E, Saglio G, Watzinger F, Lion T, van Dongen JJ, Hokland P, Gabert J. Evaluation of candidate control genes for diagnosis and residual disease detection in leukemic patients using 'real-time' quantitative reverse-transcriptase polymerase chain reaction (RQ-PCR) - a Europe against cancer program. Leukemia 2003;17(12):2474-86.

[30] Schmittgen TD, Livak KJ. Analyzing real-time PCR data by the comparative $\mathrm{C}(\mathrm{T})$ method. Nature Protocols 2008;3(6):1101-8.

[31] Ludwig T, Ossig R, Graessel S, Wilhelmi M, Oberleithner H, Schneider SW. The electrical resistance breakdown assay determines the role of proteinases in tumor cell invasion. American Journal of Physiology Renal Physiology 2002;283(2):F319-27.

[32] Goerge T, Barg A, Schnaeker E-M, Poppelmann B, Shpacovitch V, Rattenholl A, Maaser C, Luger TA, Steinhoff M, Schneider SW. Tumor-derived matrix metalloproteinase1 targets endothelial proteinase-activated receptor 1 promoting endothelial cell activation. Cancer Research 2006;66(15):7766-74.

[33] Szarvas T, Jager T, Becker M, Tschirdewahn S, Niedworok C, Kovalszky I, Rubben H, Ergun S, vom Dorp F. Validation of circulating MMP-7 level as an independent prognostic marker of poor survival in urinary bladder cancer. Pathology Oncology Research: POR 2011;17(2): 325-32.

[34] Tocchi A, Parks WC. Functional interactions between matrix metalloproteinases and glycosaminoglycans. Febs J 2013;280(10):2332-41.

[35] Haro H, Crawford HC, Fingleton B, Shinomiya K, Spengler DM, Matrisian LM. Matrix metalloproteinase-7-dependent release of tumor necrosis factor-alpha in a model of herniated disc resorption. J Clin Invest 2000;105(2):143-50. 
[36] King J, Zhao J, Clingan P, Morris D. Randomised double blind placebo control study of adjuvant treatment with the metalloproteinase inhibitor, Marimastat in patients with inoperable colorectal hepatic metastases: Significant survival advantage in patients with musculoskeletal sideeffects. Anticancer Research 2003;23(1B):639-45.

[37] Cathcart J, Pulkoski-Gross A, Cao J. Targeting Matrix Metalloproteinases in Cancer: Bringing New Life to Old Ideas. Genes \& Diseases 2015;2(1):26-34.
[38] Gupta GP, Massague J. Cancer metastasis: Building a framework. Cell 2006;127(4):679-95.

[39] Rodriguez Faba O, Palou-Redorta J, Fernandez-Gomez JM, Algaba F, Eiro N, Villavicencio H, Vizoso FJ. Matrix Metalloproteinases and Bladder Cancer: What is New? ISRN Urology 2012;2012:581539. 